\title{
Prognostic role of GPER/Ezrin in triple-negative breast cancer is associated with menopausal status
}

\author{
Shuang $\mathrm{Ye}^{1 *}$, Yuanyuan $\mathrm{Xu}^{1 *}$, Jiehao $\mathrm{Li}^{1}$, Shuhui Zheng ${ }^{2}$, Peng Sun ${ }^{3}$ and Tinghuai Wang ${ }^{1}$ \\ 'Department of Physiology, Zhongshan School of Medicine, Sun Yat-Sen University, Guangzhou, China \\ ${ }^{2}$ Research Center for Translational Medicine, The First Affiliated Hospital of Sun Yat-Sen University, Guangzhou, China \\ ${ }^{3}$ Department of Pathology, Sun Yat-Sen University Cancer Center, State Key Laboratory of Oncology in South China, Collaborative Innovation Center for \\ Cancer Medicine, Guangzhou, China
}

Correspondence should be addressed to P Sun or T Wang: sunpeng1@sysucc.org.cn or wangth@mail.sysu.edu.cn

*(S Ye and Y Xu contributed equally to this paper as co-first authors)

\begin{abstract}
The role of G protein-coupled estrogen receptor 1 (GPER) signaling, including promotion of Ezrin phosphorylation (which could be activated by estrogen), has not yet been clearly identified in triple-negative breast cancer (TNBC). This study aimed to evaluate the prognostic value of GPER and Ezrin in TNBC patients. Clinicopathologic features including age, menopausal status, tumor size, nuclear grade, lymph node metastasis, AJCC TNM stage, and ER, PR and HER-2 expression were evaluated from 249 TNBC cases. Immunohistochemical staining of GPER and Ezrin was performed on TNBC pathological sections. Kaplan-Meier analyses, as well as logistic regressive and Cox regression model tests were applied to evaluate the prognostic significance between different subgroups. Compared to the GPER-low group, the GPER-high group exhibited higher TNM staging $(P=0.021)$, more death $(P<0.001)$, relapse $(P<0.001)$ and distant events $(P<0.001)$. Kaplan-Meier analysis showed that GPER-high patients had a decreased OS $(P<0.001)$, PFS $(P<0.001)$, LRFS $(P<0.001)$ and DDFS $(P<0.001)$ than GPER-low patients. However, these differences in prognosis were not statistically significant in post-menopausal patients (OS, $P=0.8617$; PFS, $P=0.1905 ;$ LRFS, $P=0.4378$; DDFS,$P=0.2538$ ). There was a significant positive correlation between GPER and Ezrin expression level $(R=0.508, P<0.001)$ and the effect of Ezrin on survival prognosis corresponded with GPER. Moreover, a multivariable analysis confirmed that GPER and Ezrin level were both significantly associated with poor DDFS (HR: $0.346,95 \% \mathrm{Cl} 0.182-0.658, P=0.001$; HR: 0.320, $95 \% \mathrm{Cl} 0.162-0.631, P=0.001)$. Thus, overexpression of GPER and Ezrin may contribute to aggressive behavior and indicate unfavorable prognosis in TNBC; this may correspond to an individual's estrogen levels.
\end{abstract}

\section{Key Words}

- triple-negative breast cancer

- GPER

- Ezrin

- prognosis

- estrogen

\section{Background}

Triple-negative breast cancer (TNBC) is negative for estrogen receptor (ER), progesterone receptor (PR) and human epidermal growth receptor 2 (HER-2), and accounts for $15-20 \%$ of all breast cancers (1). Due to this lack of the common therapeutic targets, TNBCs are associated with the worst prognosis and one of the highest risks of metastasis among all subtypes of breast cancer $(2,3)$.

Further, several population-based studies have shown that TNBC often presents at a younger age despite lack of ER, and older patients may have a better outcome https://ec.bioscientifica.com

https://doi.org/10.1530/EC-19-0164 (c) 2019 The authors Published by Bioscientifica Ltd

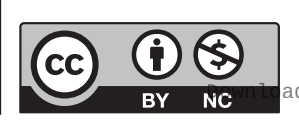

This work is licensed under a Creative Commons Attribution-NonCommercial 4.0 International License. ded from Bioscientifica.com at 04/26/2023 12:06:00PM 
when compared with their younger counterparts $(4,5)$. An epidemiology survey of basal-like breast cancer has revealed that the alterations of hormones throughout a woman's life are linked to the risk of developing TNBC (6). Overall, while these recent studies suggest that estrogen plays a role in the management of TNBC, the mechanism of estrogen involvement remains undefined.

Although TNBCs lack classic nuclear ERs, more evidence demonstrates estrogen could influence cell proliferation and migration elicited by combining steroid hormone receptors such as $\mathrm{G}$ protein-coupled estrogen receptor 1 (GPER), ER $\beta$ or estrogen-related receptors $(7,8,9,10)$.

GPER, also known as $\mathrm{G}$ protein-coupled receptor 30 (GPR30), used to be considered an orphan receptor. Later, two groups independently proved that GPER binds to and is activated by estradiol, and in response, initiates intracellular signaling cascades $(10,11,12)$. Although controversies still exist on the specificity of the binding between GPER and estrogen, most studies currently conclude that GPER is driven by estrogen and is compatible with the pattern of ligand-receptor binding $(13,14)$. Our previous study showed that treatment with 17b-estradiol (E2) in MDA-MB-231 TNBC cells resulted in Ezrin-dependent cytoskeleton rearrangement, and elicited a stimulatory effect on cell migration and invasion. Importantly, we observed that Ezrin phosphorylation, cell migration and invasion activated by E2 could be significantly inhibited by silencing GPER signaling (15), indicating that E2 induces the phosphorylation of Ezrin protein by GPER to mediate important cellular activities in TNBC cells. Moreover, the expression of GPER in TNBC is extensive and its downstream signaling pathway has been proved to be involved in proliferation, metastasis and angiogenesis in TNBC $(16,17)$. However, the function of GPER in TNBC remains controversial. As reported in some studies, activation of GPER may suppress the epithelialmesenchymal transition of TNBC cells (18).

Therefore, the current study aimed to determine GPER and Ezrin immunopositivity in a cohort of TNBC patients, to understand the characteristics and prognostic value of GPER, and the possible relationship between these two in TNBC. Furthermore, we investigated a potential association of GPER and Ezrin with the clinicopathological parameters of TNBC.

\section{Materials and methods}

\section{Specimen characteristics and ethical approval}

FFPE tissue was derived from 249 patients diagnosed with TNBC at our institution from 1999 to 2011. The eligibility criteria were pathologically confirmed TNBC, underwent primary tumor resection after diagnosis and availability of follow-up data. For each case, detailed clinicopathological characteristics including age, menopausal status, tumor size, nuclear grade, lymph node metastasis (LNM) and AJCC TNM stage were routinely abstracted from the medical record and are shown in compliance with the REMARK criteria (19) in Tables 1 and 2. This study was approved by the Ethics Committee of Sun Yat-Sen University Cancer Center, and all patients had provided written informed consent for their data and surgical specimens to be used for research purposes.

\section{Immunohistochemistry}

In the histopathological reports, GPER and Ezrin were evaluated with immunohistochemistry. Formalin-fixed paraffin-embedded tumor tissues were conventionally sectioned and then deparaffinized, hydrated and endogenous peroxidase activity was blocked with $3 \% \mathrm{H}_{2} \mathrm{O}_{2}$ for $10 \mathrm{~min}$. Pressure cooker antigen retrieval was carried out in EDTA for GPER $(\mathrm{pH}=9.0)$ and Ezrin $(\mathrm{pH}=8.0)$ for $2 \mathrm{~min} 30 \mathrm{~s}$ to enhance immunoreactivity. Samples were then incubated with a GPER primary antibody (1:100 dilution, rabbit polyclonal, ab39742, Abcam) and Ezrin antibody (1:100 dilution, rabbit polyclonal, NBP2-16396, Novus, CO, USA) overnight at $4^{\circ} \mathrm{C}$. After washing with phosphate-buffered saline (PBS), the slides were treated with a peroxidase anti-rabbit secondary antibody (Zhongshan Golden Bridge Biotechnology, Beijing, China) at $37.5^{\circ} \mathrm{C}$ for $30 \mathrm{~min}$. Subsequently, DAB (Zhongshan Golden Bridge Biotechnology, Beijing, China) was used to stain the slides. Endometrial carcinoma tissue and renal cell carcinoma tissue were used as positive staining control, respectively, which has been demonstrated to express GPER and Ezrin (20, 21). Two positive control tissues exchanged the primary antibody to check for unspecific staining as the negative control (Supplementary Fig. 1, see section on supplementary data given at the end of this article).

\section{IHC scoring}

Two independent pathologists blindly scored all the specimens by consensus. The IHC staining was quantified by applying the immunoreactive score (22), which is calculated by multiplying the staining intensity (grade as 0 , negative; 1 , weak; 2 , moderate; and 3 , strong staining) and percentage of positively stained cells $(0 ;<5 \%$; 
Table 1 GPER positivity in TNBC as correlated with clinicopathological factor.

\begin{tabular}{|c|c|c|c|c|}
\hline & All & GPER-Iow & GPER-high & $p^{*}$ \\
\hline \multicolumn{5}{|l|}{ Menopause status } \\
\hline Pre-menopause & $196(78.7)$ & $140(79.5)$ & $56(76.7)$ & 0.619 \\
\hline Post-menopause & $53(21.3)$ & $36(20.5)$ & $17(23.3)$ & \\
\hline \multicolumn{5}{|l|}{ Tumor size (pT, cm) } \\
\hline pT1 & 76 (30.5) & 48 (27.3) & $28(38.4)$ & 0.113 \\
\hline pT2 & $147(59.0)$ & $110(62.5)$ & $37(50.7)$ & \\
\hline pT3 & $20(8.0)$ & $15(8.5)$ & $5(6.8)$ & \\
\hline pT4 & $6(2.4)$ & $2(1.1)$ & $4(5.5)$ & \\
\hline \multicolumn{5}{|l|}{ Nuclear grade } \\
\hline II & 48 (19.3) & 34 (19.3) & $14(19.2)$ & 0.980 \\
\hline III & $201(80.7)$ & $142(80.7)$ & $59(80.8)$ & \\
\hline \multicolumn{5}{|l|}{ LNM $^{\#}$} \\
\hline pNO & $133(53.4)$ & $101(57.4)$ & $32(43.8)$ & 0.101 \\
\hline $\mathrm{pN} 1$ & $58(23.3)$ & $41(23.3)$ & $17(23.3)$ & \\
\hline $\mathrm{pN} 2$ & 34 (13.7) & $21(11.9)$ & $13(17.8)$ & \\
\hline pN3 & $24(9.6)$ & $13(7.4)$ & $11(15.1)$ & \\
\hline \multicolumn{5}{|l|}{ TNM staging\# } \\
\hline I & $38(15.3)$ & $27(15.3)$ & $11(15.1)$ & 0.021 \\
\hline Ila & $108(43.4)$ & $80(45.5)$ & $28(38.4)$ & \\
\hline $\mathrm{IIb}$ & $40(16.1)$ & $33(18.8)$ & 7 (9.6) & \\
\hline IIIa & 34 (13.7) & $22(12.5)$ & $12(16.4)$ & \\
\hline IIIb & $5(2.0)$ & $1(0.6)$ & $4(5.5)$ & \\
\hline IIIC & $24(9.6)$ & $13(7.4)$ & $11(15.4)$ & \\
\hline \multicolumn{5}{|l|}{ Local treatment } \\
\hline Mastectomy & $84(33.7)$ & $59(33.5)$ & $25(34.2)$ & 0.373 \\
\hline Quadrantectomy & $13(5.2)$ & $7(4.0)$ & $6(8.2)$ & \\
\hline Mastectomy + RT & $149(59.8)$ & $107(60.8)$ & $42(57.5)$ & \\
\hline Quadrantectomy + RT & $3(1.2)$ & $3(1.7)$ & $0(0)$ & \\
\hline \multicolumn{5}{|l|}{ Chemotherapy } \\
\hline Yes & 179 (71.9) & $127(72.2)$ & $52(71.2)$ & 0.882 \\
\hline No & $70(28.1)$ & $49(27.8)$ & $21(28.8)$ & \\
\hline \multicolumn{5}{|l|}{ Death } \\
\hline Yes & $64(25.7)$ & $31(17.6)$ & $33(45.2)$ & $<0.001$ \\
\hline No & $185(74.3)$ & $145(82.4)$ & $40(54.8)$ & \\
\hline \multicolumn{5}{|l|}{ Relapse event } \\
\hline Yes & $34(13.7)$ & $14(8.0)$ & $20(27.4)$ & $<0.001$ \\
\hline No & $215(86.3)$ & $162(92.0)$ & $53(71.6)$ & \\
\hline \multicolumn{5}{|l|}{ Distant event } \\
\hline Yes & $53(21.3)$ & $18(10.2)$ & 35 (47.9) & $<0.001$ \\
\hline No & $196(78.7)$ & $158(89.8)$ & $38(52.1)$ & \\
\hline
\end{tabular}

5-24\%; 25-49\%; 50-74\%; 75-100\%). An ROC curve of the survival result for all intensity levels was plotted to generate the optimal cut-off value of GPER and Ezrin expression (Supplementary Table 1). The immunoreactive score of IRS $=0.8$ was used to distinguish between low and high expression of both GPER and Ezrin.

\section{Statistical analyses}

Chi-squared test or Fisher's exact test was used to analyze the association of GPER and Ezrin status with clinicopathological variables. End points including local relapse, distant metastasis, death and any progression were used to calculate the LRFS (local relapsefree survival), DDFS (distant disease-free survival), OS (overall survival) and PFS (progression-free survival). Kaplan-Meier survival analysis and log-rank test were utilized to compare the survival outcome. Multivariate analysis using a Cox proportional hazard model was performed based on variables with a $P$ value of $<0.05$ from the logistic regression. All significance level of statistics was set at 0.05 except multivariate model which was set at 0.01 . https://ec.bioscientifica.com

https://doi.org/10.1530/EC-19-0164
(C) 2019 The authors Published by Bioscientifica Ltd

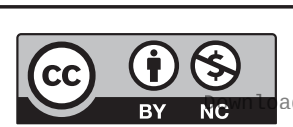

This work is licensed under a Creative Commons Attribution-NonCommercial 4.0 International License. ded from Bioscientifica.com at 04/26/2023 12:06:00PM via free access 
Table 2 Ezrin positivity in TNBC as correlated to clinicopathological factor.

\begin{tabular}{|c|c|c|c|c|}
\hline & All & Ezrin-low & Ezrin-high & $P *$ \\
\hline \multicolumn{5}{|l|}{ Menopause status } \\
\hline Pre-menopause & 196 (78.7) & $134(79.3)$ & $62(77.5)$ & 0.747 \\
\hline Post-menopause & $53(21.3)$ & 35 (20.7) & $18(22.5)$ & \\
\hline \multicolumn{5}{|l|}{ Tumor size (pT, cm) } \\
\hline pT1 & 76 (30.5) & $48(28.4)$ & $28(35.0)$ & 0.166 \\
\hline рT2 & $147(59.0)$ & $104(61.5)$ & $43(53.8)$ & \\
\hline рT3 & $20(8.0)$ & $15(8.9)$ & $5(6.3)$ & \\
\hline pT4 & $6(2.4)$ & $2(1.2)$ & $4(5.0)$ & \\
\hline \multicolumn{5}{|l|}{ Nuclear grade } \\
\hline II & 48 (19.3) & 37 (21.9) & $11(13.8)$ & 0.128 \\
\hline III & $201(80.7)$ & $132(78.1)$ & 69 (27.7) & \\
\hline \multicolumn{5}{|l|}{ LNM $^{\#}$} \\
\hline pNO & $133(53.4)$ & $98(58.0)$ & $35(43.8)$ & 0.136 \\
\hline pN1 & $58(23.3)$ & $38(22.5)$ & $20(25.0)$ & \\
\hline pN2 & $34(13.7)$ & $20(11.8)$ & $14(17.5)$ & \\
\hline pN3 & $24(9.6)$ & $13(7.7)$ & $11(13.8)$ & \\
\hline \multicolumn{5}{|l|}{ TNM staging\# } \\
\hline I & 38 (15.3) & $26(15.4)$ & $12(15.0)$ & 0.221 \\
\hline Ila & $108(43.4)$ & $78(46.2)$ & $30(37.5)$ & \\
\hline $\mathrm{IIb}$ & $40(16.1)$ & $30(17.8)$ & $20(12.5)$ & \\
\hline IIla & $34(13.7)$ & $20(11.8)$ & $14(17.5)$ & \\
\hline $\mathrm{IIIb}$ & $5(2.0)$ & $2(1.2)$ & $3(3.8)$ & \\
\hline IIIC & $24(9.6)$ & $13(7.7)$ & $11(13.8)$ & \\
\hline \multicolumn{5}{|l|}{ Local treatment } \\
\hline Mastectomy & $84(33.7)$ & $60(35.5)$ & $24(30.0)$ & 0.190 \\
\hline Quadrantectomy & $13(5.2)$ & $6(3.6)$ & $7(8.8)$ & \\
\hline Mastectomy + RT & $149(59.8)$ & $100(59.2)$ & 49 (61.3) & \\
\hline Quadrantectomy + RT & $3(1.2)$ & $3(1.8)$ & $0(0)$ & \\
\hline \multicolumn{5}{|l|}{ Chemotherapy } \\
\hline Yes & 179 (71.9) & $118(69.8)$ & $61(76.3)$ & 0.292 \\
\hline No & $70(28.1)$ & $51(30.2)$ & $19(23.8)$ & \\
\hline \multicolumn{5}{|l|}{ Death } \\
\hline Yes & $64(25.7)$ & $29(17.2)$ & $35(43.8)$ & $<0.001$ \\
\hline No & 185 (74.3) & $140(82.8)$ & $45(56.2)$ & \\
\hline \multicolumn{5}{|l|}{ Relapse event } \\
\hline Yes & $34(13.7)$ & $17(10.1)$ & $17(21.3)$ & 0.016 \\
\hline No & $215(86.3)$ & 152 (89.9) & $63(78.7)$ & \\
\hline \multicolumn{5}{|l|}{ Distant event } \\
\hline Yes & $53(21.3)$ & $15(8.9)$ & $38(47.5)$ & $<0.001$ \\
\hline No & 196 (78.7) & $154(91.1)$ & $42(52.5)$ & \\
\hline
\end{tabular}

\section{Results}

\section{Patient characteristics}

During the period of study, 249 cases of primitive invasive breast cancer were diagnosed as TNBC for which the clinicopathological characteristics were available. As shown in Tables 1 and 2, all patients in our study (249/249, $100.0 \%$ ) were assigned as intermediate (G2) or high grade (G3). For TNM grouping, a total of 249 cases were enrolled with $15.2 \%(38 / 249)$ at stage I, 59.5\% (148/249) at stage II and $25.3 \%(63 / 249)$ at stage III. Overall median age at diagnosis was 47 years (range, 23-80 years).
More than two-thirds $(n=196,78.7 \%)$ of patients were in pre-menopause.

\section{Immunoreactivity of GPER and Ezrin in TNBC tissue}

Examples of negative (0), weak (1), moderate (2) and strong (3) GPER and Ezrin staining intensity are shown in Figs 1 and 2. GPER and Ezrin staining were detected in the large majority $(177 / 249,71.1 \% ; 185 / 249,74.3 \%)$ of TNBC tissue samples. In general, the expression level of GPER and Ezrin were found to be different in cancer nests and adjacent tissues in positive specimens. According to the

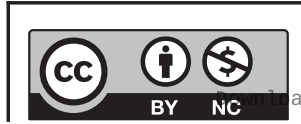

This work is licensed under a Creative Commons Attribution-NonCommercial 4.0 International License. ded from Bioscientifica.com at 04/26/2023 12:06:00PM via free access 

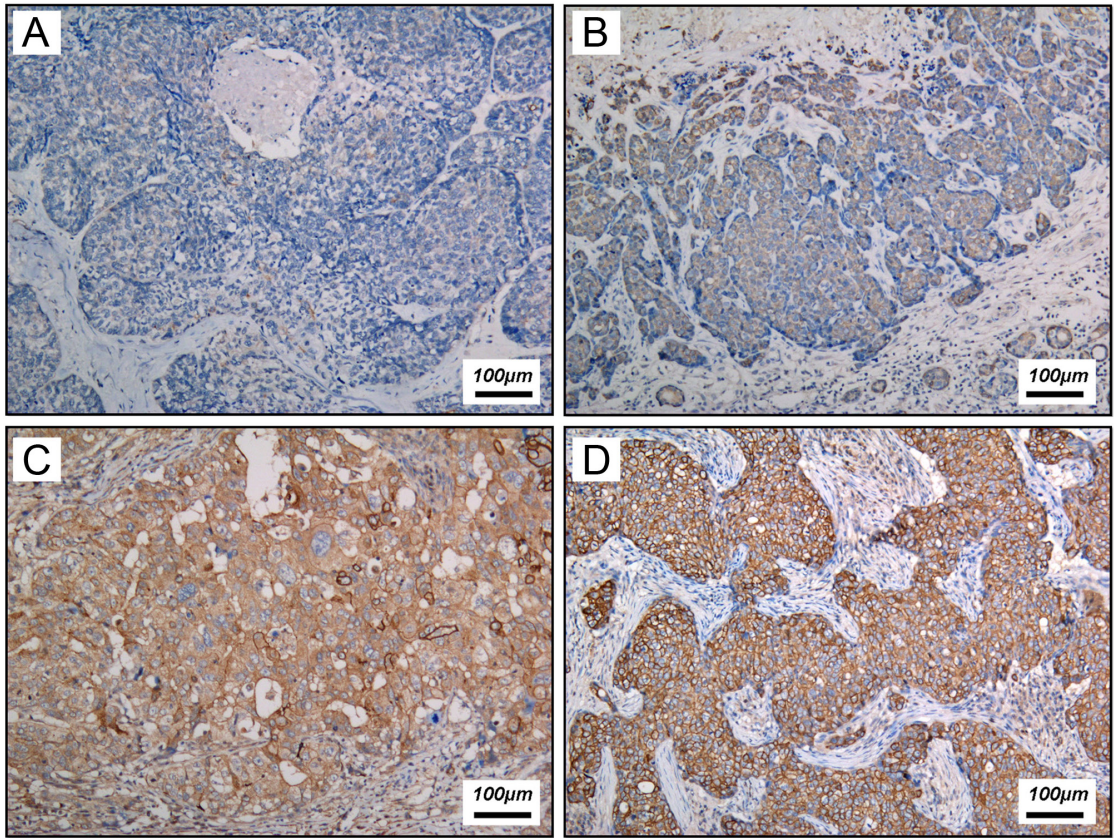

\section{igure 1}

GPER expression in TNBC tissue. Representative IHC figures of GPER grade: (A) negative $(0),(B)$ weak (1), (C) moderate (2) and (D) strong staining (3). Scale bar equals $100 \mu \mathrm{m}$.

cut-off IHC score, low and high GPER expression levels were found in $70.7 \%(176 / 249)$ and $29.3 \%(73 / 249)$ of patients, respectively, and 32.1\% (80/249) of specimens had high expression of Ezrin (Tables 1 and 2). Among them, 55.4\% (138/249) of cases were GPER/Ezrin-low expression and 16.9\% (42/249) were GPER/Ezrin-high. Overall, GPER and Ezrin were detected in both cytoplasm and cell membranes of all positively stained sections. The expression level of GPER and Ezrin were found to be different in cancer nests and adjacent tissues (data not shown).

The association of GPER and Ezrin expression with clinicopathological factors

The association of GPER and Ezrin expression with some clinicopathologic variables was assessed. As shown in Tables 1 and 2, high GPER expression was significantly
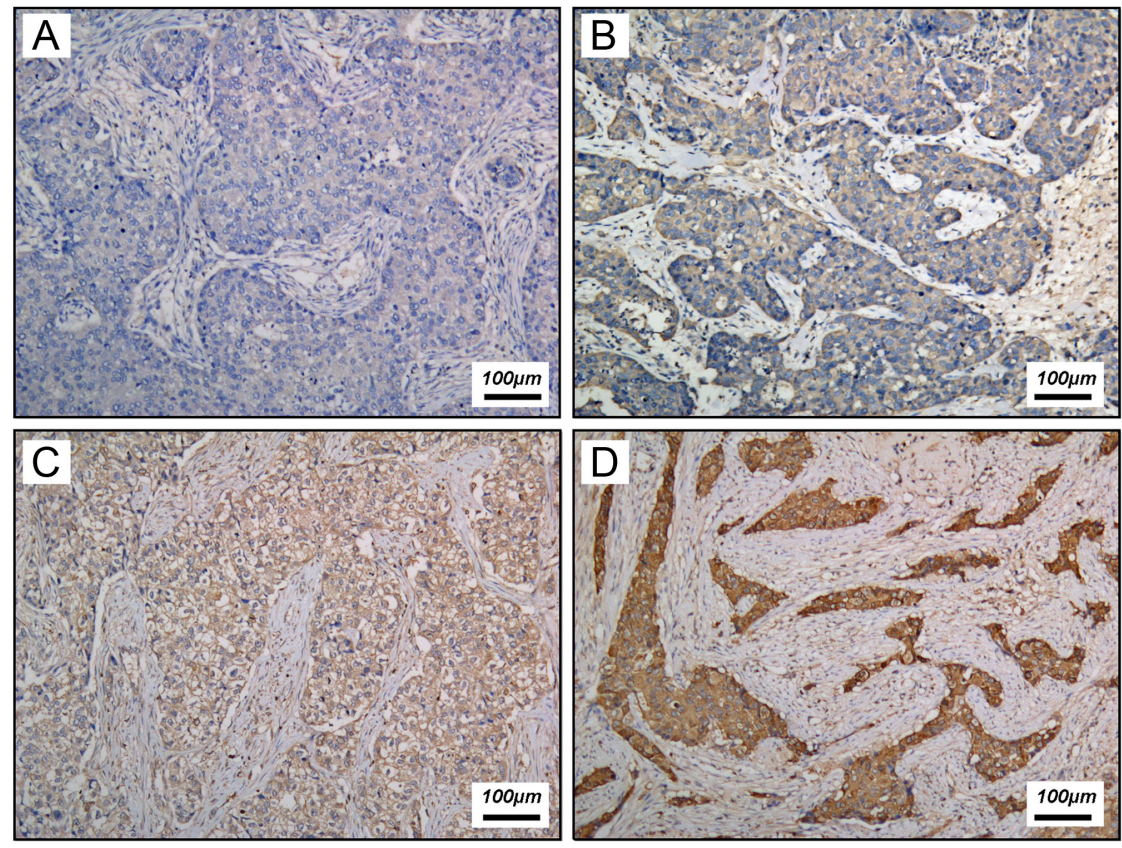

\section{Figure 2}

Ezrin expression in TNBC tissue. Representative IHC figures of Ezrin grade: (A) negative ( 0$),(B)$ weak (1), (C) moderate (2) and (D) strong staining (3). Scale bar equals $100 \mu \mathrm{m}$. https://ec.bioscientifica.com https://doi.org/10.1530/EC-19-0164 (c) 2019 The authors Published by Bioscientifica Ltd
This work is licensed under a Creative Commons Attribution-NonCommercial 4.0 International License. ded from Bioscientifica.com at 04/26/2023 12:06:00PM 
A
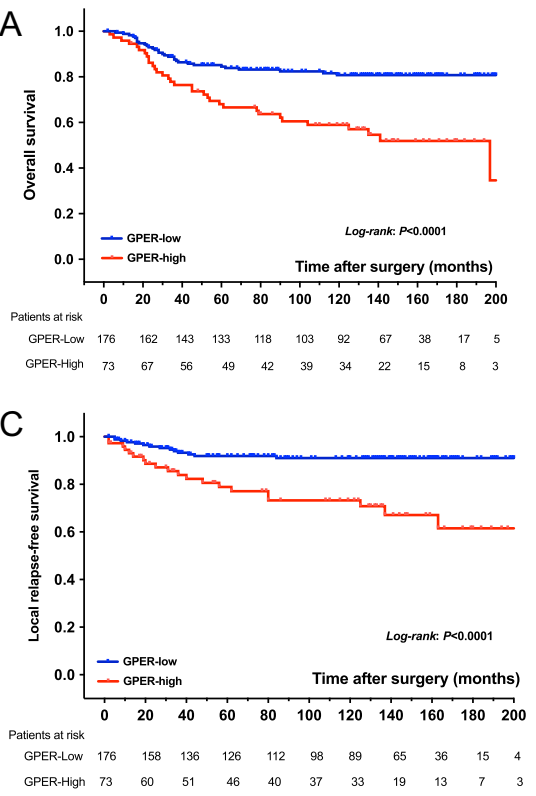

B

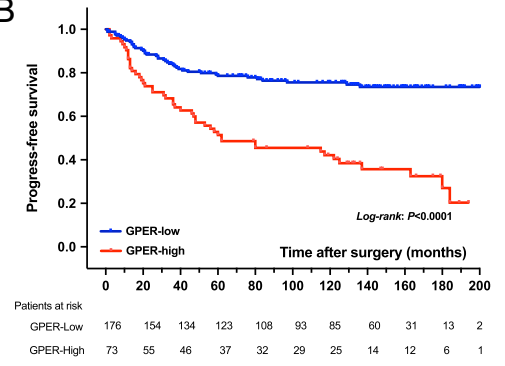

D

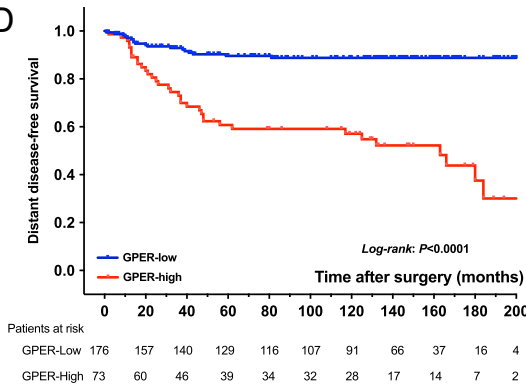

Figure 3

Kaplan-Meier curves comparing survival outcome of TNBC patients with high and low GPER expression. Patients with high GPER expression had a significantly lower OS (A), PFS (B), LRFS (C) and DDFS (D) rate than those with low GPER expression. associated with high TNM staging (I, 15.1 vs 15.3\%; IIa, 38.4 vs $45.5 \%$; IIb, 9.6 vs $18.8 \%$; IIIa, 16.4 vs $12.5 \%$; IIIb, 5.5 vs $0.6 \%$; IIIc, 15.4 vs $7.4 \% ; P=0.021)$, more death (45.2 vs $17.6 \% ; P<0.001$ ), relapse (27.4 vs $8.0 \% ; P<0.001$ ) and distant events (47.9 vs $10.2 \% ; P<0.001)$. Similarly, a higher ratio of death (45.3 vs $17.2 \%$; $P<0.001)$, local relapse (21.3 vs $10.1 \% ; P=0.016)$ and distant metastasis (47.5 vs $8.9 \%$; $P<0.001$ ) was observed in high Ezrin patients, but not in other variables.

\section{The relationship between GPER, Ezrin and long-term} survival outcome

Kaplan-Meier analysis showed that in all 249 cases, patients with high GPER expression in tumors had a significantly lower OS $(P<0.001)$, PFS $(P<0.001)$, LRFS $(P<0.001)$ and DDFS $(P<0.001)$ rate than those with low GPER expression (Fig. 3). However, further analysis of patients stratified by menopause status demonstrated that,

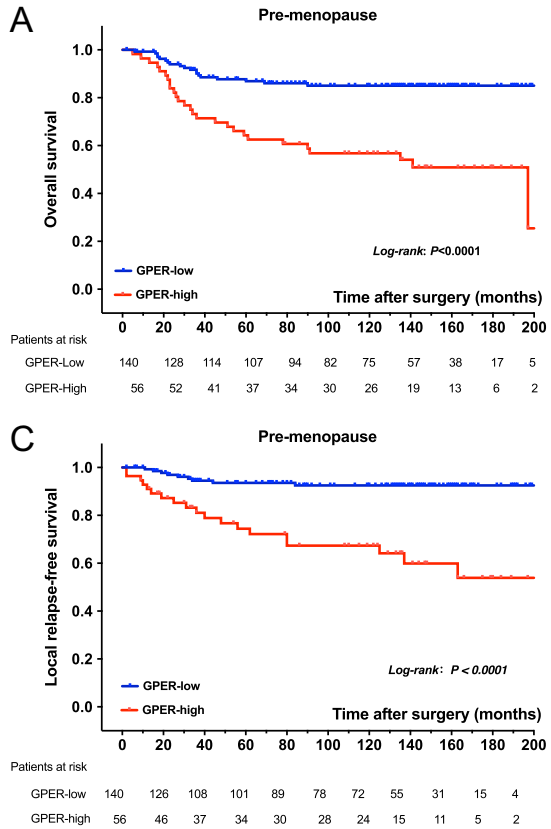

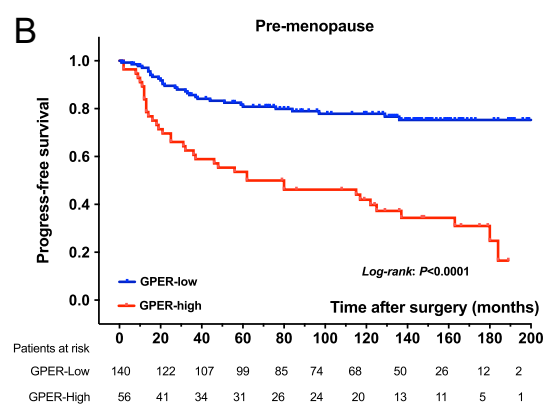

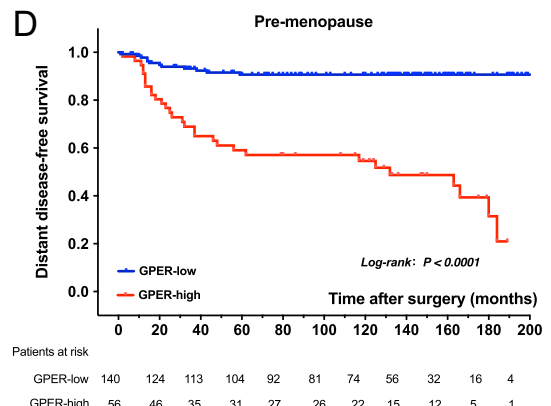

Figure 4

Kaplan-Meier curves comparing survival outcome of pre-menopause TNBC patients with high and Iow GPER expression. In the pre-menopause subgroup, patients with high GPER expression had a significantly lower OS (A), PFS (B), LRFS (C) and DDFS (D) rate than those with low GPER expression. https://ec.bioscientifica.com https://doi.org/10.1530/EC-19-0164 (c) 2019 The authors Published by Bioscientifica Ltd

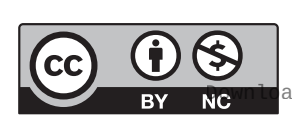

This work is licensed under a Creative Commons Attribution-NonCommercial 4.0 International License. ded from Bioscientifica.com at 04/26/2023 12:06:00PM via free access 
A
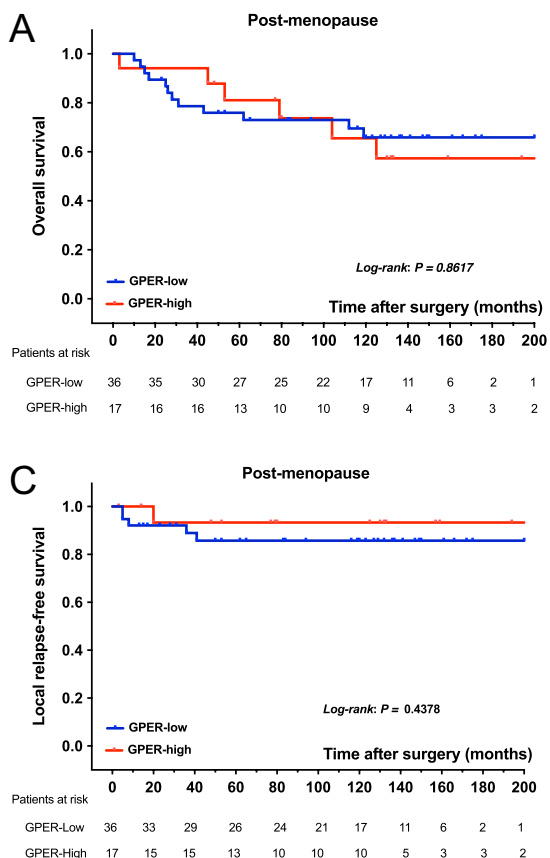
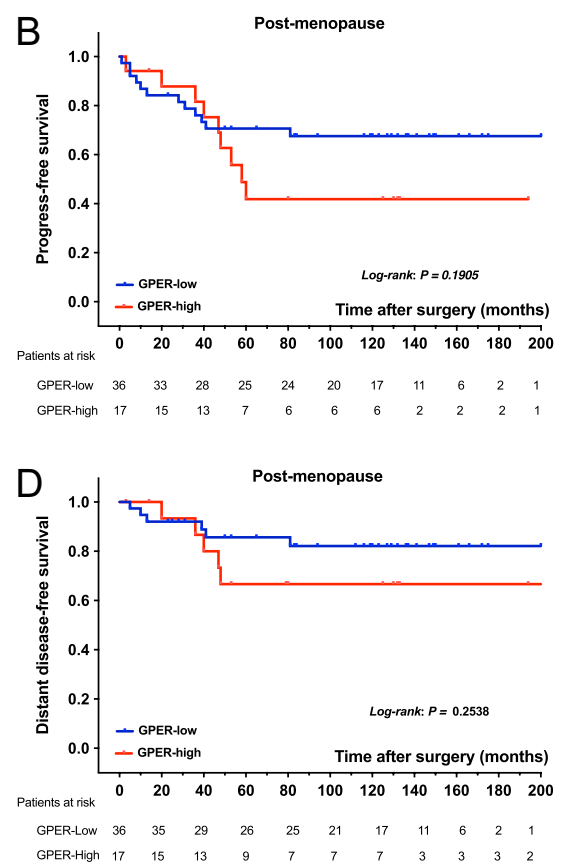

\section{Figure 5}

Kaplan-Meier curves comparing survival outcome of post-menopause TNBC patients with high and low GPER expression. In the post-menopause subgroup, there were no significant differences in OS (A), PFS (B), LRFS (C) and DDFS (D) between high and low GPER expression patients. in the pre-menopause subgroup, the patients with high GPER expression had a significantly lower OS $(P<0.001)$, PFS $(P<0.001)$, LRFS $(P<0.001)$ and DDFS $(P<0.001)$ rate than those with low GPER expression (Fig. 4), but no statistically significant difference was observed in terms of OS $(P=0.8617)$, PFS $(P=0.1905)$, LRFS $(P=0.4378)$ and DDFS $(P=0.2538)$ rate between the patients with high and low GPER expression in the post-menopause group (Fig. 5). There is no interaction effect of survival outcome between GPER level and menopause status $(P=0.716$; Supplementary Fig. 2).

Spearman correlation showed that there is positive relationship between the full range expression of GPER and Ezrin in our TNBC samples (Table 3, $R=0.508$, $P<0.001)$. An effect on survival prognosis by Ezrin, similar to the GPER effect, was observed. The high expression of Ezrin also could significantly decrease the patients' OS $(P<0.001)$, PFS $(P<0.001)$, LRFS $(P=0.0122)$ and DDFS $(P<0.001)$ rate (Fig. 6$)$. The statistical differences in the prognostic value of Ezrin disappeared in post-menopause patients (Figs 7 and 8).

Table 3 Positive relationship between expression of GPER and Ezrin.

\begin{tabular}{|c|c|c|c|c|c|}
\hline Ezrin & & GPER-Iow & GPER-high & $R^{*}$ & $P$ \\
\hline Low & 169 (67.9) & $138(78.4)$ & $31(42.5)$ & 0.508 & $<0.001$ \\
\hline High & $80(32.1)$ & $38(21.6)$ & $42(57.5)$ & & \\
\hline
\end{tabular}

By further subgrouping, we found that high co-expression of GPER/Ezrin was significantly linked to the worst OS $(P<0.001)$, PFS $(P=0.269)$, LRFS $(P=0.001)$ and DDFS $(P<0.001)$ of patients compared to the low co-expression of GPER/Ezrin group (Fig. 9).

We then used logistic regression and Cox regression to identify the prognostic value of GPER, Ezrin expression and other clinicopathologic variables in univariate and multivariate models. As presented in Table 4, which was adjusted for those risk factors, the multivariate analysis revealed that high GPER still independently predicted poor PFS (HR $=0.393 ; 95 \%$ CI $0.246-0.629 ; P<0.001)$, LRFS $(\mathrm{HR}=0.329 ; 95 \%$ CI $0.153-0.704 ; P=0.004)$ and DDFS $(\mathrm{HR}=0.346 ; 95 \%$ CI $0.182-0.658 ; P=0.001)$. In addition, Ezrin expression also remained the prognostic factor for DDFS (HR $=0.320 ; 95 \%$ CI $0.162-0.631 ; P=0.001$ ).

\section{Discussion}

In our study, most cases presented with higher nuclear grades and worse TNM staging, which is characteristic of TNBC, together with a high degree of malignancy and rapid progression (23). Large-scale clinical studies have found that TNBC has a higher risk of recurrence and metastasis, and a worse prognosis in young women than in post-menopausal patients (4). Similar to the literature reported $(4,24)$, most of our patients are pre-menopausal women.

To the best our knowledge, until now, the clinical relevance of GPER expression in TNBC remains controversial.

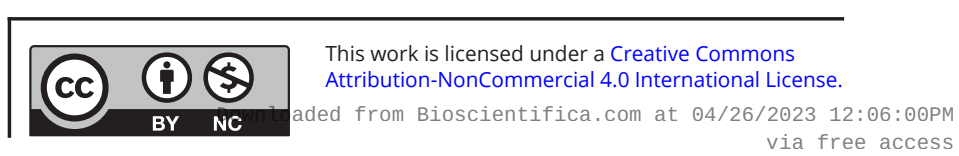


A

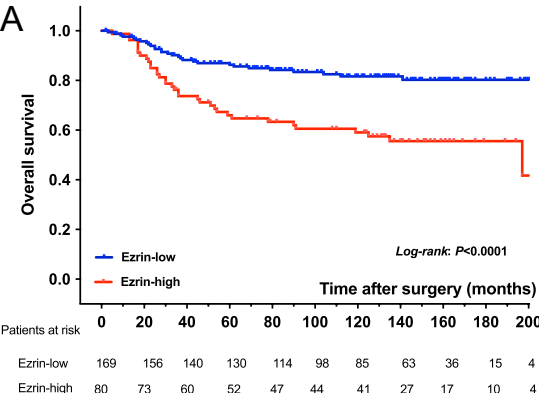

C

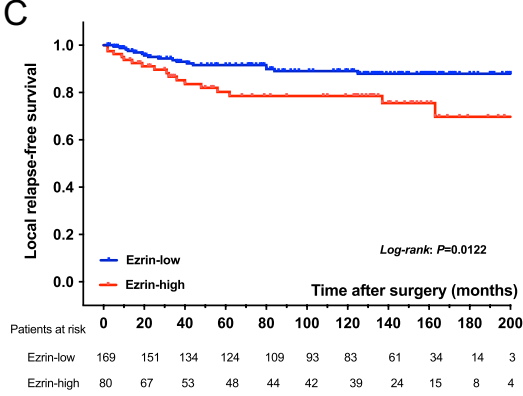

B

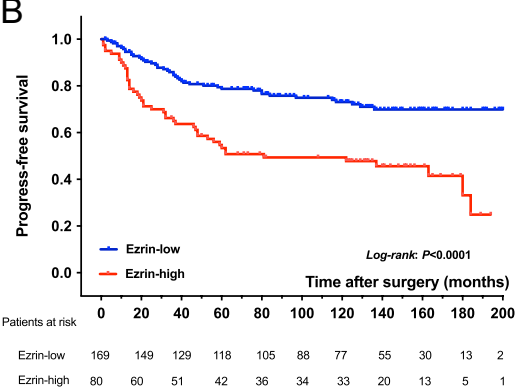

D

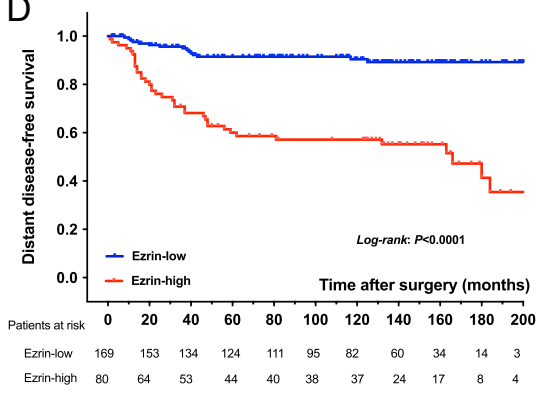

\section{Figure 6}

Kaplan-Meier curves comparing survival outcome of TNBC patients with high and low Ezrin expression. Patients with high Ezrin expression had a significantly lower OS (A), PFS (B), LRFS (C) and DDFS (D) rate than those with low Ezrin expression.
Some studies suggest that GPER expression is not associated with or inhibits the progression of TNBC $(18,25)$. We suspected this phenomenon may be related to the nonspecific activity of the GPER-specific agonist G-1 (26). Most studies found that GPER is prevalent in TNBC and associated with young age, and possibly with prognosis $(17,27)$. Our data also found GPER was mainly located in cancer nests and was significantly correlated with patients' TNM staging and survival outcomes: evidence which links the expression of GPER with TNBC clinical status.
When we focus on the patient's long-term survival, the data showed that the high expression of GPER correlated with high risk of death, local relapse and distant metastasis in TNBC. Further, we noted that GPER expression appears to be lower in younger TNBC patients with better prognosis. Therefore, we divided all patients into pre-menopausal and post-menopausal groups, and then separately studied the effect of GPER expression on outcome. According to the Kaplan-Meier analyses, it is highly likely that the role of GPER in predicting
A

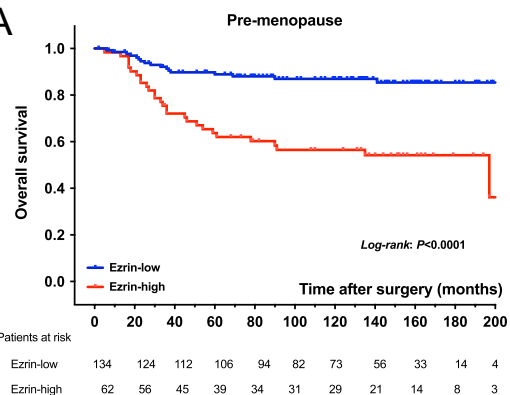

C

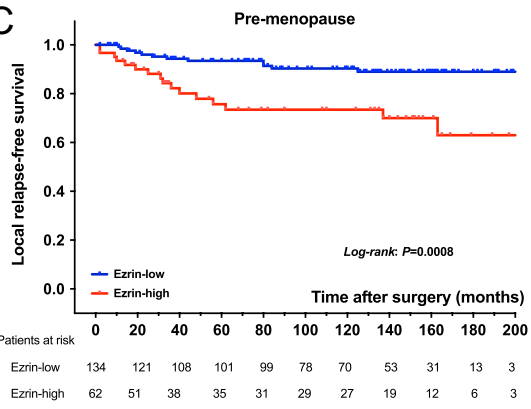

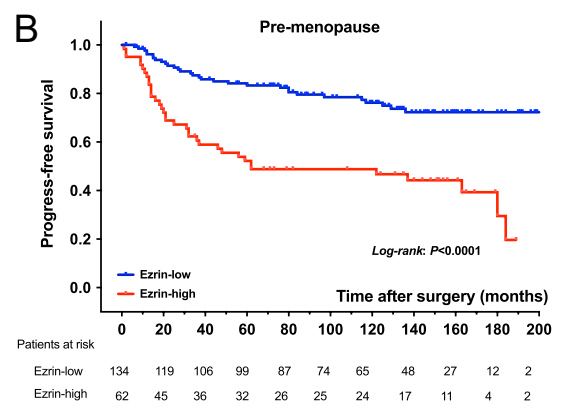

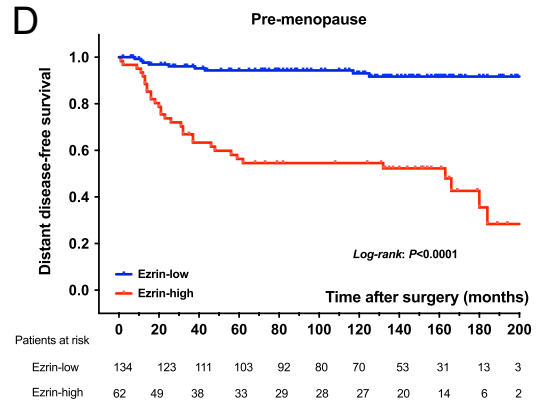

\section{Figure 7}

Kaplan-Meier curves comparing survival outcome of pre-menopause TNBC patients with high and low Ezrin expression. In the pre-menopause subgroup, patients with high Ezrin expression had a significantly lower OS (A), PFS (B), LRFS (C) and DDFS (D) rate than those with low Ezrin expression. 
A
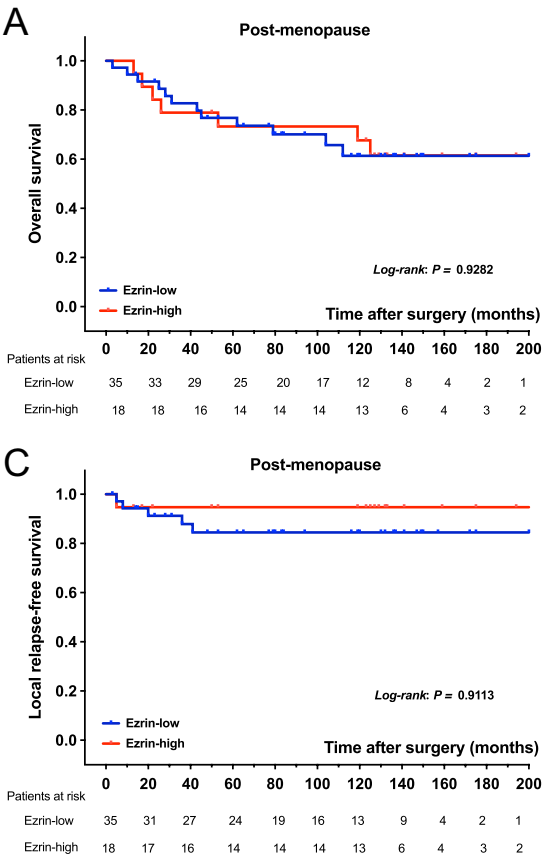

B
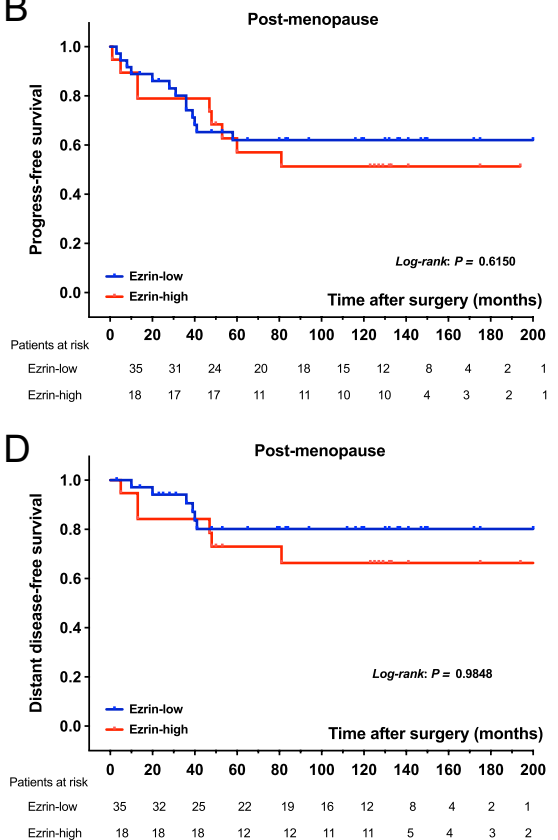

\section{Figure 8}

Kaplan-Meier curves comparing survival outcome of post-menopause TNBC patients with high and low Ezrin expression. In the post-menopause subgroup, there were no significant differences in OS (A), PFS (B), LRFS (C) and DDFS (D) between high and low Ezrin expression patients. the prognosis of TNBC was mediated by estrogen. The mechanism may be related to an estrogen-activated GPER downstream cascade reaction, which promotes tumor cell proliferation, migration and invasion $(7,27,28)$.

However, Ezrin belongs to the actin-binding protein family and participates in cell behavior by modulating cytoskeleton rearrangement to promote the formation of membrane protrusions, such as filopodia, lamellipodia (29). Ezrin could be phosphorylated more after $17 \beta$-estradiol activates GPER in ER(-) breast cancer cells, such as SK-BR-3 and MDA-MB-231, as previously described (15). In this study, the positive relationship and similar prognostic role between GPER and Ezrin was identified. We hypothesize that for those TNBC women patients who are younger and have a higher GPER expression, high levels of estrogen in the body may promote tumorigenesis by activating signaling pathways downstream of GPER including Ezrin phosphorylation. By conducting a comprehensive analysis of the odds ratio of various clinical factors in the multivariate model, we found that only the DDFS survival rate is affected by both GPER and Ezrin. Although the reason of insufficient sample size can't be excluded, it also provides evidence for GPER to play a role in distant metastasis events.

In conclusion, we propose high GPER expression is a poor maker for young TNBC patients. GPER also might
A

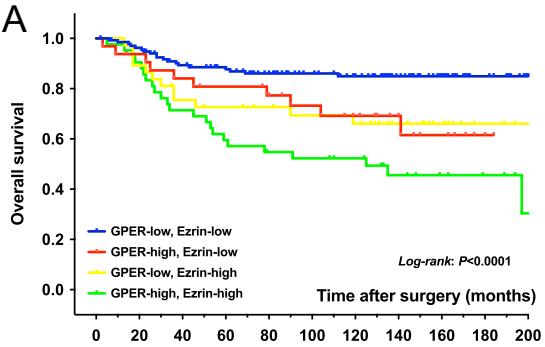

C

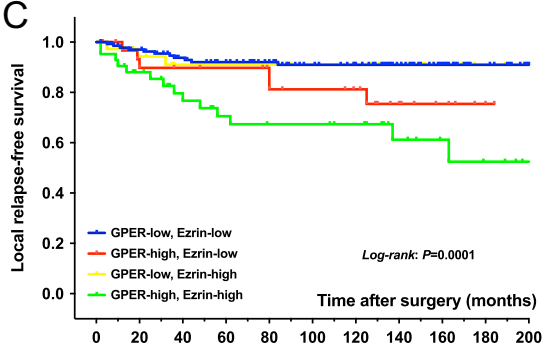

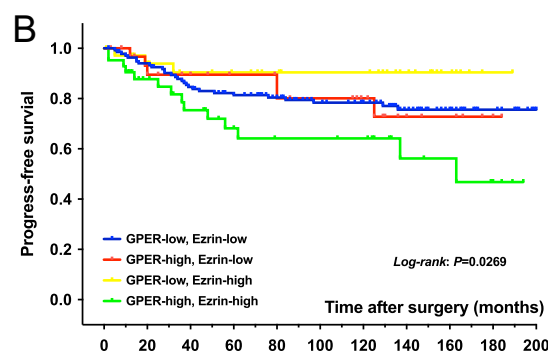

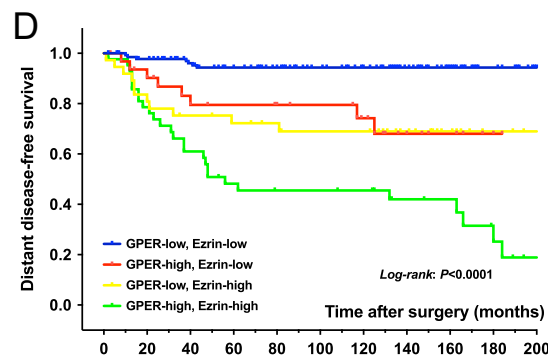

Figure 9

Kaplan-Meier curves comparing survival outcome of TNBC patients with co-expression of GPER/Ezrin. Patients with high co-expression of GPER/Ezrin had significantly lower OS (A), PFS (B), LRFS (C) and DDFS (D) rates than those with low co-expression of GPER/Ezrin group. https://ec.bioscientifica.com https://doi.org/10.1530/EC-19-0164 (c) 2019 The authors Published by Bioscientifica Ltd
This work is licensed under a Creative Commons Attribution-NonCommercial 4.0 International License. ded from Bioscientifica.com at 04/26/2023 12:06:00PM 
.

Table 4 Univariate and multivariate survival analyses of clinicopathologic factors, GPER and Ezrin expression.

\begin{tabular}{|c|c|c|c|c|c|c|c|}
\hline & \multicolumn{3}{|c|}{ Univariate model } & \multicolumn{4}{|c|}{ Multivariate model } \\
\hline & $P^{*}$ & OR & $95 \% \mathrm{Cl}$ for OR & $p^{* \star}$ & $\mathrm{HR}$ & $\beta$ & $95 \% \mathrm{Cl}$ for $\mathrm{HR}$ \\
\hline \multicolumn{8}{|l|}{ Any event } \\
\hline Age & 0.836 & 0.997 & $0.974-1.022$ & & & & \\
\hline Site (left vs right) & 0.527 & 1.182 & $0.704-1.986$ & & & & \\
\hline Nuclear grade (G2 vs G3) & 0.001 & 0.203 & $0.083-0.500$ & 0.001 & 0.240 & -1.425 & $0.104-0.566$ \\
\hline Tumor size & 0.088 & 1.146 & $0.980-1.340$ & & & & \\
\hline LNM (no vs yes) & $<0.001$ & 0.369 & $0.216-0.629$ & 0.072 & 0.621 & -0.476 & $0.370-1.043$ \\
\hline TNM (I/II vs III) & $<0.001$ & 0.187 & $0.101-0.345$ & 0.002 & 0.436 & -0.831 & $0.257-0.740$ \\
\hline GPER (low vs high) & $<0.001$ & 0.173 & $0.096-0.313$ & $<0.001$ & 0.393 & -0.933 & $0.246-0.629$ \\
\hline Ezrin (low vs high) & $<0.001$ & 0.274 & $0.156-0.479$ & 0.141 & 0.697 & -0.361 & $0.431-1.127$ \\
\hline \multicolumn{8}{|l|}{ Death } \\
\hline Age & 0.489 & 1.009 & $0.983-1.036$ & & & & \\
\hline Site (left vs right) & 0.634 & 0.871 & $0.493-1.538$ & & & & \\
\hline Nuclear grade (G2 vs G3) & 0.002 & 0.153 & $0.046-0.511$ & 0.007 & 0.201 & -1.606 & $0.063-0.644$ \\
\hline Tumor size & 0.021 & 1.215 & $1.030-1.434$ & 0.023 & 1.168 & 0.156 & $1.022-1.336$ \\
\hline LNM (no vs yes) & $<0.001$ & 0.218 & $0.118-0.402$ & 0.064 & 0.533 & -0.629 & $0.274-1.036$ \\
\hline TNM (I/II vs III) & $<0.001$ & 0.119 & $0.063-0.228$ & 0.002 & 0.359 & -1.023 & $0.190-0.679$ \\
\hline GPER (low vs high) & $<0.001$ & 0.259 & $0.142-0.473$ & 0.025 & 0.528 & -0.639 & $0.301-0.924$ \\
\hline Ezrin (low vs high) & $<0.001$ & 0.266 & $0.147-0.483$ & 0.073 & 0.595 & -0.519 & $0.337-1.336$ \\
\hline \multicolumn{8}{|l|}{ Relapse event } \\
\hline Age & 0.197 & 0.977 & $0.943-1.012$ & & & & \\
\hline Site (left vs right) & 0.808 & 1.094 & $0.530-2.258$ & & & & \\
\hline Nuclear grade (G2 vs G3) & 0.049 & 0.230 & $0.053-0.994$ & 0.050 & 0.239 & -1.433 & $0.057-1.001$ \\
\hline Tumor size & 0.950 & 1.007 & $0.881-1.250$ & & & & \\
\hline LNM (no vs yes) & 0.005 & 0.336 & $0.158-0.716$ & 0.209 & 0.569 & -0.564 & $0.236-1.372$ \\
\hline TNM (I/II vs III) & $<0.001$ & 0.235 & $0.111-0.498$ & 0.023 & 0.368 & -0.998 & $0.156-0.871$ \\
\hline GPER (low vs high) & $<0.001$ & 0.229 & $0.108-0.485$ & 0.004 & 0.329 & -1.113 & $0.153-0.704$ \\
\hline Ezrin (low vs high) & 0.019 & 0.414 & $0.199-0.863$ & 0.752 & 0.884 & -0.124 & $0.410-1.904$ \\
\hline \multicolumn{8}{|l|}{ Distant event } \\
\hline Age & 0.301 & 0.985 & $0.957-1.014$ & & & & \\
\hline Site (left vs right) & 0.529 & 0.823 & $0.448-1.511$ & & & & \\
\hline Nuclear grade (G2 vs G3) & 0.010 & 0.201 & $0.060-0.676$ & 0.005 & 0.184 & -1.695 & $0.056-0.602$ \\
\hline Tumor size & 0.075 & 1.165 & $0.985-1.379$ & & & & \\
\hline LNM (no vs yes) & $<0.001$ & 0.310 & $0.165-0.585$ & 0.070 & 0.525 & -0.644 & $0.262-1.053$ \\
\hline TNM (I/II vs III) & $<0.001$ & 0.174 & $0.090-0.334$ & 0.022 & 0.449 & -0.801 & $0.227-0.889$ \\
\hline GPER (low vs high) & $<0.001$ & 0.124 & $0.063-0.242$ & 0.001 & 0.346 & -1.061 & $0.182-0.658$ \\
\hline Ezrin (low vs high) & $<0.001$ & 0.108 & $0.054-0.214$ & 0.001 & 0.320 & -1.139 & $0.162-0.631$ \\
\hline
\end{tabular}

provide a new pathway for the prevention and treatment of all types of breast cancer, especially in those $\mathrm{ER}(+)$ breast cancer patients who have had a relapse or a drugresistant event. Further studies on every molecular type of breast cancer could better characterize patients according to the expression of GPER.

\section{Supplementary data}

This is linked to the online version of the paper at https://doi.org/10.1530/ EC-19-0164.

\section{Declaration of interest}

The authors declare that there is no conflict of interest that could be perceived as prejudicing the impartiality of the research reported.

\section{Funding}

This study was supported by National Natural Science Foundation of China (Grant numbers: 81372818, 81572585).

\section{Acknowledgements}

The authors acknowledge the assistance of the Prof. Jiehua He of the Department of Pathology at Sun Yat-sen University Cancer Center.

\section{References}

1 Rabanal C, Ruiz R, Neciosup S \& Gomez H. Metronomic chemotherapy for non-metastatic triple negative breast cancer: selection is the key. World Journal of Clinical Oncology 20178 437-446. (https://doi.org/10.5306/wjco.v8.i6.437)

2 Kirkpatrick P. Targeting triple-negative breast cancer. Nature Reviews Drug Discovery 20098 21-21. (https://doi.org/10.1038/nrd2789) https://ec.bioscientifica.com

https://doi.org/10.1530/EC-19-0164 (c) 2019 The authors Published by Bioscientifica Ltd

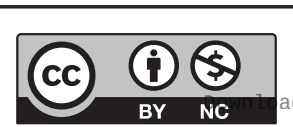

This work is licensed under a Creative Commons Attribution-NonCommercial 4.0 International License. ded from Bioscientifica.com at 04/26/2023 12:06:0๑PM via free access 
3 Brouckaert O, Wildiers H, Floris G \& Neven P. Update on triplenegative breast cancer: prognosis and management strategies. International Journal of Women's Health 20124 511-520. (https://doi. org/10.2147/IJWH.S18541)

4 Aapro M \& Wildiers H. Triple-negative breast cancer in the older population. Annals of Oncology 201223 (Supplement 6) vi52-vi55. (https://doi.org/10.1093/annonc/mds189)

5 Anderson WF, Jatoi I \& Devesa SS. Distinct breast cancer incidence and prognostic patterns in the NCI's SEER program: suggesting a possible link between etiology and outcome. Breast Cancer Research and Treatment 200590 127-137. (https://doi.org/10.1007/s10549004-3777-3)

6 Millikan RC, Newman B, Tse CK, Moorman PG, Conway K, Dressler LG, Smith LV, Labbok MH, Geradts J, Bensen JT, et al. Epidemiology of basal-like breast cancer. Breast Cancer Research and Treatment 2008109 123-139. (https://doi.org/10.1007/s10549-0079632-6)

7 Yu T, Liu M, Luo H, Wu C, Tang X, Tang S, Hu P, Yan Y, Wang Z \& Tu G. GPER mediates enhanced cell viability and motility via nongenomic signaling induced by 17 beta-estradiol in triple-negative breast cancer cells. Journal of Steroid Biochemistry and Molecular Biology 2014143 392-403. (https://doi.org/10.1016/j.jsbmb.2014.05.003)

8 Deblois G \& Giguere V. Oestrogen-related receptors in breast cancer: control of cellular metabolism and beyond. Nature Reviews: Cancer 201313 27-36. (https://doi.org/10.1038/nrc3396)

9 Ma R, Karthik GM, Lovrot J, Haglund F, Rosin G, Katchy A, Zhang X, Viberg L, Frisell J, Williams C, et al. Estrogen receptor beta as a therapeutic target in breast cancer stem cells. Journal of the National Cancer Institute 2017109 1-14. (https://doi.org10.1093/ jnci/djw236)

10 Filardo EJ. Epidermal growth factor receptor (EGFR) transactivation by estrogen via the G-protein-coupled receptor, GPR30: a novel signaling pathway with potential significance for breast cancer. Journal of Steroid Biochemistry and Molecular Biology 200280 231-238. (https://doi.org/10.1016/S0960-0760(01)00190-X)

11 Revankar CM, Cimino DF, Sklar LA, Arterburn JB \& Prossnitz ER. A transmembrane intracellular estrogen receptor mediates rapid cell signaling. Science 2005307 1625-1630. (https://doi.org/10.1126/ science.1106943)

12 Thomas P, Pang Y, Filardo EJ \& Dong J. Identity of an estrogen membrane receptor coupled to a $\mathrm{G}$ protein in human breast cancer cells. Endocrinology 2005146 624-632. (https://doi.org/10.1210/ en.2004-1064)

13 Gaudet HM, Cheng SB, Christensen EM \& Filardo EJ. The G-protein coupled estrogen receptor, GPER: the inside and inside-out story. Molecular and Cellular Endocrinology 2015418 207-219. (https://doi. org/10.1016/j.mce.2015.07.016)

14 Barton M, Filardo EJ, Lolait SJ, Thomas P, Maggiolini M \& Prossnitz ER. Twenty years of the G protein-coupled estrogen receptor GPER: historical and personal perspectives. Journal of Steroid Biochemistry and Molecular Biology 2018176 4-15. (https://doi. org/10.1016/j.jsbmb.2017.03.021)

15 Zhou K, Sun P, Zhang Y, You X, Li P \& Wang T. Estrogen stimulated migration and invasion of estrogen receptor-negative breast cancer cells involves an ezrin-dependent crosstalk between $\mathrm{G}$ proteincoupled receptor 30 and estrogen receptor beta signaling. Steroids 2016111 113-120. (https://doi.org/10.1016/j.steroids.2016.01.021)

16 Luo HJ, Luo P, Yang GL, Peng QL, Liu MR \& Tu G. G-protein coupled estrogen receptor 1 expression in primary breast cancers and its correlation with clinicopathological variables. Journal of Breast Cancer 201114 185-190. (https://doi.org/10.4048/jbc.2011.14.3.185)

17 Steiman J, Peralta EA, Louis S \& Kamel O. Biology of the estrogen receptor, GPR30, in triple negative breast cancer. American Journal of Surgery 2013206 698-703. (https://doi.org/10.1016/j. amjsurg.2013.07.014)

18 Chen ZJ, Wei W, Jiang GM, Liu H, Wei WD, Yang X, Wu YM, Liu H, Wong CK, Du J, et al. Activation of GPER suppresses epithelial mesenchymal transition of triple negative breast cancer cells via NF-kappaB signals. Molecular Oncology 201610 775-788. (https://doi. org/10.1016/j.molonc.2016.01.002)

19 Sauerbrei W, Taube SE, McShane LM, Cavenagh MM \& Altman DG. Reporting recommendations for tumor marker prognostic studies (REMARK): an abridged explanation and elaboration. Journal of the National Cancer Institute 2018110 803-811. (https://doi.org/10.1093/ jnci/djy088)

20 Yu N, Fu S, Liu Y, Xu Z, Liu Y, Hao J, Wang B \& Zhang A. miR-96 suppresses renal cell carcinoma invasion via downregulation of Ezrin expression. Journal of Experimental and Clinical Cancer Research 2015 34 107. (https://doi.org/10.1186/s13046-015-0224-8)

21 Skrzypczak M, Schuler S, Lattrich C, Ignatov A, Ortmann O \& Treeck O. G protein-coupled estrogen receptor (GPER) expression in endometrial adenocarcinoma and effect of agonist G-1 on growth of endometrial adenocarcinoma cell lines. Steroids 201378 1087-1091. (https://doi.org/10.1016/j.steroids.2013.07.007)

22 Peng J, Ou Q, Wu X, Zhang R, Zhao Q, Jiang W, Lu Z, Wan D, Pan Z \& Fang Y. Expression of voltage-gated sodium channel Nav1.5 in non-metastatic colon cancer and its associations with estrogen receptor (ER)-beta expression and clinical outcomes. Chinese Journal of Cancer 201736 89. (https://doi.org/10.1186/s40880-017-0253-0)

23 Dent R, Trudeau M, Pritchard KI, Hanna WM, Kahn HK, Sawka CA, Lickley LA, Rawlinson E, Sun P \& Narod SA. Triple-negative breast cancer: clinical features and patterns of recurrence. Clinical Cancer Research 200713 4429-4434. (https://doi.org/10.1158/1078-0432. CCR-06-3045)

24 Gluz O, Liedtke C, Gottschalk N, Pusztai L, Nitz U \& Harbeck N. Triple-negative breast cancer - current status and future directions. Annals of Oncology 200920 1913-1927. (https://doi.org/10.1093/ annonc/mdp492)

25 Aiad HA, Wahed MM, Asaad NY, El-Tahmody M \& Elhosary E. Immunohistochemical expression of GPR30 in breast carcinoma of Egyptian patients: an association with immunohistochemical subtypes. Acta Pathologica, Microbiologica, et Immunologica Scandinavica 2014122 976-984. (https://doi.org/10.1111/ apm.12241)

26 Lv X, He C, Huang C, Hua G, Wang Z, Remmenga SW, Rodabough KJ, Karpf AR, Dong J, Davis JS, et al. G-1 Inhibits breast cancer cell growth via targeting colchicine-binding site of tubulin to interfere with microtubule assembly. Molecular Cancer Therapeutics 201716 1080-1091. (https://doi.org/10.1158/1535-7163.MCT-160626)

27 Lappano R, Pisano A \& Maggiolini M. GPER function in breast cancer: an overview. Frontiers in Endocrinology 20145 66. (https://doi. org/10.3389/fendo.2014.00066)

28 Filardo EJ, Quinn JA, Frackelton AR, Jr \& Bland KI. Estrogen action via the $G$ protein-coupled receptor, GPR30: stimulation of adenylyl cyclase and cAMP-mediated attenuation of the epidermal growth factor receptor-to-MAPK signaling axis. Molecular Endocrinology 2002 16 70-84. (https://doi.org/10.1210/mend.16.1.0758)

29 Jiang P, Enomoto A \& Takahashi M. Cell biology of the movement of breast cancer cells: intracellular signalling and the actin cytoskeleton. Cancer Letters 2009284 122-130. (https://doi.org/10.1016/j. canlet.2009.02.034)

Received in final form 3 April 2019

Accepted 17 April 2019

Accepted Preprint published online 18 April 2019

https://ec.bioscientifica.com https://doi.org/10.1530/EC-19-0164
(C) 2019 The authors Published by Bioscientifica Ltd

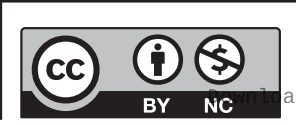

This work is licensed under a Creative Commons Attribution-NonCommercial 4.0 International License. ded from Bioscientifica com at 04/26/2023 12:06:00PM 